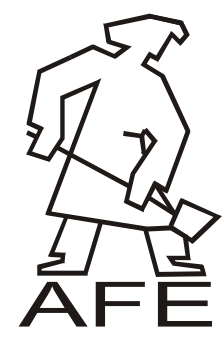

FOUNDRY ENGINEERING

DOI: 10.2478/v10266-012-0108-8
ISSN (2299-2944)

Volume 12

Issue $4 / 2012$

\title{
Specificity of SPC Procedures Application in Foundry in Aspect of Data Acquisition and Data Exploration
}

\author{
Z. Ignaszak*, R. Sika \\ CAD/CAE Laboratory and Division of Foundry, Poznań University of Technology, \\ Piotrowo Str. 3, 61-138 Poznań, Poland \\ * Corresponding author. E-mail address: zenon.ignaszak@put.poznan.pl
}

Received 17.07.2012; accepted in revised form 03.09.2012

\begin{abstract}
The paper presents an analysis of SPC (Statistical Process Control) procedures usability in foundry engineering. The authors pay particular attention to the processes complexity and necessity of correct preparation of data acquisition procedures. Integration of SPC systems with existing IT solutions in area of aiding and assistance during the manufacturing process is important. For each particular foundry, methodology of selective SPC application needs to prepare for supervision and control of stability of manufacturing conditions, regarding specificity of data in particular "branches” of foundry production (Sands, Pouring, Metallurgy, Quality).
\end{abstract}

Keywords: Application of information technology to the foundry industry, Statistical process control, Shewhart control charts, Data acquisition, Data mining

\section{Introduction}

Statistical Process Control (SPC) is not limited only to the inspection (monitoring) of the process itself, as the name could suggest. As a set of actions, it originates from the post-war period and initially was developed mainly in Japan, thanks to application of pioneer work by Deming and Shewhart [1]. Relation between deviations of parameters of the given process and the reference values, especially in form of a diagram, allows to predict potential deviations from the expected course of the process and perform the corrective actions in due course. By assumption, SPC methods can be introduced to any branch of industry or economy. Foundry is also cited as an area of their application [2].

SPC consists in parallel or exclusive use of some number of techniques, including, among others, procedures of supply (delivery) control, planning of experiments, techniques of regression, analyses based on Pareto guidelines, control charts etc. By definition and circulating literature reports, one can conclude that application of control charts allows to "early sight" when the given process starts to behave in a "non-standard" manner and, if needed, to react quickly. It also can be used for verification and control of the stability of the manufacturing process in time.

The basic question still remains: what is a criterion of a "non-standard" behaviour and what should be understood as a "quick reaction". The authors of this paper think that specificity of the foundry processes causes a necessity of paying the closest attention to this problem during implementation of SPC in a foundry. It is also important because presently most of the audit procedures conducted by exacting customers contain a mandatory point - application of the SPC procedures. It is often done with automatic transfer of the customer "academic" background about 
the SPC in the industry of e.g. machining to other manufacturing technologies, so also to the foundry.

This paper evaluates these practices and tries to answer a question - how much is this proceeding right. The paper refers to previous works, where thorough attention was paid to effective Data Acquisition in the foundry processes, with examples of specific foundries [3-11]. It needs to be stated, with a high probability, that SPC tools are an excellent mean for evaluation and control of the stability of the foundry processes.

\section{SPC in a foundry, chance or a formal requirement?}

Globally understood casting quality is a concept related to requirements (specifications) of the receiver, by assumption a complete document resulting from operational tasks of the casted part [12]. In case of detected gas-shrinkage discontinuities in the casting structure, it does not need to be classified as an evidently defected product [12-14]. A casting testing using NDT (Non-Destructive Testing) methods and having an appropriate certificate is given to the receiver. If after a finishing working by machining there are no visual defects detected, use of a casting for normal operation is permitted. In [15], an often insufficient state of an effective communication between manufacturers and recipients (designers) of castings and too insignificant role of synergy on particular stages was shown [12-15,25].

Considering the above mentioned statements, final casting quality does not have a strict definition. Referred to the receiving conditions, it is a synthesis of indirect parameters, while their complex nature and impact on this quality introduces a sort of confusion into "academic" treatment of the SPC procedures. Not always, not to say often, exceed of the reference level of the given parameter of the selected process (e.g. pouring temperature) needs to end with an evident result in form of a defected casting (failure). This fact often stands against the classic "philosophy” of the SPC, based upon geometrical and dimensional parameters, where exceed of the tolerance field is equal to a defect and rejection of the considered part.

Back to holistically understood casting quality, one needs to refer to input values of the processes, from quality of materials bought from suppliers (moulding sands and bentonites, binders, scrap, alloy elements etc.), to materials processed in further stages (green sand, prepared casting mould, liquid alloy of an appropriate composition and metallurgical quality, etc.). The supplier is responsible for the quality of supplied materials, presenting appropriate conformity certificates. The responsibility is relayed on foundries, which should selectively perform a quality check, according to the GIGO rule (Garbage In, Garbage Out - garbage at the input will result in garbage at the end). The foundry should further care about control procedures for relevant parameters of materials processing, in area related to customer receiving conditions (terms of customer acceptance, TCA), adjusted to accepted manufacturing technology (terms adapted to technology, TAT).

It is a fact, that customer-receiver of the castings is in turn responsible for a quality of manufactured machines in particular industry sectors. Each stage of a product processing in above mentioned delivery and service chain should be controlled according to strictly established procedures, supported with appropriate standards. It suits mostly a case of castings used in automotive manufacturing. According to producers from these sectors, foundries should increase a usage of SPC methods, along with an assessment of process capability indices $C_{p}$ and $C_{p k}$.

SPC is a statistical method, which is used for evaluation and supervision of the production stability, most often in a form of an average value, range or standard deviation of an examined parameter, which is measurable and unequivocally indicates fulfilment of a certain quality criterion by the product. The most important SPC tool (out of so-called "magnificent seven” of SPC) is the Shewhart Control Chart (SCC). The SCCs are linear diagrams, on which control limits and warning control are put. SCCs allow the on-line monitoring of parameters of series production. They show, in a follow-up graphical manner, irregularities occurring in the production in a form of variability of above mentioned statistical parameters during the process. An advantage is taken from the fact that variables occurring in this process of stability/quality control are of random character, so supporting role of statistical methods is advisable and expectations are formulated towards it [16].

Specific career of the SPC is related to global automotive industry. It sets high requirements regarding the product quality, productivity, competitiveness, being a synonym of a constant development. To fulfil these requirements, many vehicle manufacturers require the part suppliers to rationally adjust to technical specifications, defined in a standard of quality management for suppliers in automotive sector - ISO TS 16949 [17].

It is often a requirement of the branch standards, as in case of above mentioned automotive standards, to consciously control the quality of castings. Most often the customer requires implementation, or at least obeying to requirements contained in specialized standards. As the ISO/TS 16949 standard [18] states, they can be:

- FMEA (Failure mode and effects analysis) of the manufacturing process,

- $\quad$ indication of neuralgic parameters in a foundry, which can be controlled,

- $\quad$ on-line examination of causes behind the process variability,

- methods of quick detection and transmission of feedback regarding unconformities of the product/manufacturing process.

There is therefore no doubt that the SPC application is caused by increasing requirements of foundry customers, towards adjusting the production to the standards in field of design/development, production, installation and maintenance of products for automotive branch. There is also a question regarding purposefulness and rightness of SPC application - should these methods be only used formally to positively "pass" the inquiries made by customers/auditors of this industry sector? Or do the properly implemented SPC procedures bring effects of another time dimension and with different approach to connection in process control? We will try to answer this question.

Access to complete and reliable data about the course of manufacturing processes is a necessary condition to evaluate their stability and to control the product quality. It is ensured by an appropriately integrated Data Acquisition system. The authors 
have described this subject in [3-11], emphasizing a significance of completeness of database records originating from particular production "branches" and the essence of supervision of the updating of specifications regarding manufacturing processes. An importance of quick accessibility to data and their associate in a very short time was also stressed.

\subsection{Completeness of databases from production „branches” in foundry versus SPC}

It should be emphasized that each type of data can be a specific source of a new knowledge. Acquisition of a new knowledge is not always an easy task, which is presented, inter alia, in $[5,6,11]$. Recorded data should be applied for supervision and solving of specific tasks, also with computer support. Appropriate use of the data encourages its proper acquisition. Directions of data application not related to SPC (described, inter alia, in $[2,19,20]$ are validation of simulation of process course, on-line inspection and control of the process course and detection of hidden regularities occurring in the processes. Tasks aided by use of computers correspond both with hard modelling and/or soft modelling methods [2,19,21,22].

On-line inspection of parameters and quick evaluation of stability and quality of the foundry process, real-time detection of perturbations in production with possibility of control of the manufacturing processes is possible only regarding to relatively sparse number of processes forming the whole production. It is worth reminding that foundry is a very complex type of manufacturing system, where there is a high degree of variability of manufacturing processes. Therefore, recorded sets of data are dispersed and inhomogeneous [4,5]. There are processes like production of a moulding sand, moulds and cores, melting of an alloy of an appropriate chemical composition, preceded with preparation of the whole gamut of input materials, like moulding materials, scrap, alloy additions etc. The data can be collected in a classical form, as paper records or electronically in form of databases, databases files as so-called flat file databases (databases of card index file type) or as specialized data formats, assigned to separate, modern measurement systems. The last ones require decoding using auxiliary tools, which are mostly only at disposal of the hardware supplier (which brings additional costs), to use them in further analyses and reports. There are also registered data possible to archive only in form of printouts, while the supplier does not intend to make the decoding programs available.

Large sets of data may be disturbed, among other things, by lack of values and by incomplete or variously distorted data, which is a direct consequence of mistakes made by human, measuring tool/device or also computer system of Data Acquisition. Data cleaning is a very important operation [23], which can be performed during Data Acquisition in real time [4] or during filtering of already recorded data. The authors propose to equip the computer systems into algorithms, which allow to correct or to delete wrong records in real time. These operations are, among others, data translation, data glossary (hints regarding assortment, tolerance with division into assortment, casting weight etc. - integration with "handy" databases, which are completed in due time by responsible employees) and data filtering (incomplete records are omitted or completed according to special procedures) $[3-5,10]$. Operation of data cleaning is an introduction into preparation of data sets named "pilot trial” in SPC.

Design of too strict cleaning algorithms may result in a criticism from the users, which operate the A\&DM system (Acquisition and Data Mining). More information about the exemplary KMESQ-SPC system and its implementation in a foundry are presented by the authors in the chapter 4 (a full description of the system with examples is in the making [26]).

\subsection{Supervision on update of guidelines of database parameters acquisition}

Large quantities of data gathered daily by a database system A\&DM lead to discrepancy between expectations of particular users. A user (let us name him a "branch specialist") looking for a quick feedback about parameters of particular "branch" processes, e.g. about number of pours, number of defect products, number of castings returns from the customers, information about a specific casting series (user having access to his "branch" information in the database) has different expectations than the user (from quality management group) having an access to the whole database (all "branches"). The first group ("branch specialists") uses the data to evaluate the stability of parameters and their compatibility with the production plan, the second group (let us name it AQ - Assurance Quality), having broader authorities, uses the A\&DM system for global analyses of the production quality. Still, the "branch specialists" are the ones having to watch over updating the guidelines regarding the processes (e.g. implementing criterions of limiting range values for particular assortment, assessments of parameters stability, including assessments of workers realizing the measurements, records or only supervising them). Again, one should mention a "pilot trial", which has a substantial meaning in the SPC system, and a responsibility of "branch specialists" for its proper preparation and application.

"Branch specialists" are also responsible for implemented workplace instructions, procedures, specialized standards related to specific processes, unofficial settlements inside the works (official orders). Working with AQ users they form a coherent team of manufacturing process control. As it is written in $[5,19$, 21], acquisition is a broader concept than data recording and comprises of wider range of problems.

Foundries which implemented or intend to implement a system for data acquisition and exploration (A\&DM) should also make the criteria of such acquisition precise, along with instructions regarding groups of manufacturing processes, i.e. production "branches", such as: Sands, Pouring, Metallurgy and Quality, with possibility of expansion with supplementary "branches", e.g. Raw Materials (at the input), Metallurgy Metallurgical Quality, Metallurgy - Furnace Operations, Receiving Requirements (according to customers and assortments), Instructions and NDT testing results, Manufacturing Technology (definite elaborations and correction history), Manufacturing Technology Virtualization (versions of process virtualization and others considered relevant).

The fig. 1 presents an example of improper interpretation of data as a result of not complying with guidelines of instruction regarding Data Acquisition. The diagram shows different values 
of the specification limits (upper and lower) for two following time periods. Let us assume, that as a result of manufacturing technology modification, a decision has been made in a foundry to correct the position of both specification limits and move them both $5^{\circ} \mathrm{C}$ upwards for the $\mathrm{X}$ assortment. These changes are put in the diagram since the $1^{\text {st }}$ February 2012 . After only several weeks, users may not remember the correction of the tolerance limits. Then the analyses of previous data (older than 1.02.2012) will obviously lead to wrong conclusions. The authors think that tracking of the process history is one of the key conditions in preparation and application of authorized A\&DM systems. In wider perspective it will facilitate use of SPC tools and at least servicing and designing of the pilot trial using stabilizing method (trial and error) [16].

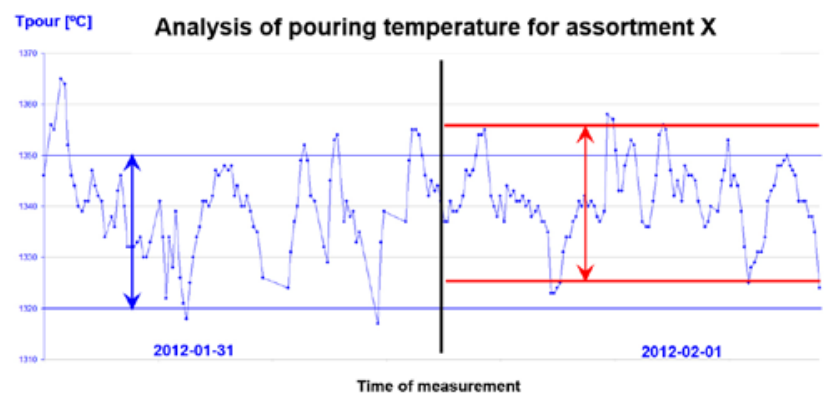

Fig. 1. Various positions of upper and lower specification limits of pouring temperature tolerance in the automatic moulding line, implemented by a "branch specialist" for the same assortment, for two different time periods as a consequence of manufacturing technology change for the assortment $\mathrm{X}$

\section{Quality control in a foundry using SPC procedures}

By assumption, SPC tools which may be used in foundries are no different than these used in manufacturing systems more „friendly” to such analysis. Mentioned above specificity of processes which comprise the casting production and Data Acquisition method requires another approach. Particular attention needs to be paid to Shewhart control charts. Attempts to implement the control charts in a foundry should be considered in a different way than in case of traditional applications, e.g. for machining industry or other production, where measured parameter exceeding an assumed specification limits of nominal dimension means disqualification of the final product qualitywise.

In foundries, one can increasingly find installed devices for automatic measurement and visualization of some parameters. Despite these possibilities of real-time identification of production parameters, in case of exceeding the specification limits defined by a "branch specialist", time of reaction is limited and the reaction can only mostly influence the next series (because of the complexity of examined process).

In such case, if it is known that a main idea of SPC is constant supervision of the process and its variability (fluctuation of average or other statistical measure of monitored parameter), interference in the process must be performed in a different way.

In foundry engineering, SPC should be used for evaluation of the process stability (its measurable stages) in the first place. Also, a possibility guaranteed by Shewhart control charts (SCC) should be maintained - SCCs contain control limits situated in an areas, which in foundry rarely result only from dimensional conditions of reception of a given part. Specification limits of parameters required by a customer or assumed by a process engineer concern the final quality, which is a set of at least several complementary parameters. Hence the two-state quality requirement (0-1) is possible formally, but in classical SPC approach it is used rather for reporting than directly for process control (unless it sanctions intermediate management staff).

SPC is based upon assumption of natural process variability (normal Gauss distribution of parameter variability). What is the meaning of natural process variability? A conclusion from the SPC classic is that a "pilot trial" should be selected (no less than 30 measurements), it does not have to, and even should not contain prepared values of a measured feature (i.e. positioned totally and quite symmetrically within the tolerance field). On the basis of calculated statistical parameters of the sample, the test control chart is designed, values of control limits are calculated along with the process capability indexes $\left(\mathrm{C}_{\mathrm{p}}, \mathrm{C}_{\mathrm{pk}}\right)$.

This is where the SPC differs from others traditional statistical methods with values of production tolerances for the measured feature defined by "branch specialists" - in SPC, a long-term stability is of concern, along with full process control, with the tolerances being more rigorous than the technological tolerances (of the "branch specialists"). SCCs should create a basis for assessment answering if the inspected process is stable (subjected to natural variability, which most often cannot be influenced), or is it behaving in a "non-standard" manner (there are incidental occurrences with causes most often possible to define). SCCs are based upon an assumption, that the manufacturing process can be subjected to interfering factors of two types [24]:

- natural factors (most often unable to be identified, random, incidental, standard, most often occurring) - related to causes of short-term variability; singular effect of variability is not high; causes of such maladjustment cannot be controlled; they are a component of the process variability and occurring in the short time intervals do not have a decisive influence on the process,

- $\quad$ unnatural factors (mostly able to be identified, not incidental, rarely occurring) - related with long-term variability causes; singular effect is relatively significant; causes of the process maladjustment can be explained by e.g. malfunction of a device dosing water in an automatic system of green sand quality control; it is a sign of abnormal process course and significant decrease in quality of green sand; causes of such maladjustment can be controlled (and removed); this kind of variability is most often assigned to identifiable causes.

Large changes in parameters may also result from non-identifiable causes and these must be treated as not included into the normal distribution. They should be excluded from the SPC analysis, until the cause is identified.

Again, the SPC classic must be referred to. Discrepancies in the control chart can be identified through: 
- $\quad$ points, which do not lay inside the area defined by control limits (or anticipating - in area of the warning limits)

- sequences of points of increasing or decreasing value,

- $\quad$ sequences of points above/below the center line - the process is not properly "adjusted" [16].

How does it look in case of pouring temperature on the automatic moulding line? One should be aware of the fact, that increase or decrease of the pouring temperature beyond the limits established by a "branch specialist" (e.g. below $1290^{\circ} \mathrm{C}$ and above $1350^{\circ} \mathrm{C}$ for tolerance field of $\pm 30^{\circ} \mathrm{C}$ ) does not have to mean that the manufactured casting will be defective. At least finding it in the manufactured series of castings (identification) is not easy in case of this method of casting production. This is an example of SPC specificity in the foundry engineering. Only a certain set of parameter values outside the specification limits can facilitate the manufacturing quality analysis when defect castings appear. So how should the casting quality be anticipatively assessed and how should the process course control for key parameters be performed? The authors propose to assess the final casting quality within the same assortment, on the basis of parameters from one production "branch" or in "inter-branch" connections (Sands, Pouring, Metallurgy, Quality) [26].

\section{4. „Pilot trial” module in SPC [26]}

Below, as an example, a module using SPC method, connected with own system for Data Acquisition and Data Exploration (KMESQ system) is presented. As a result of its application, bases for Shewhart control charts are created in form of a "pilot trial".

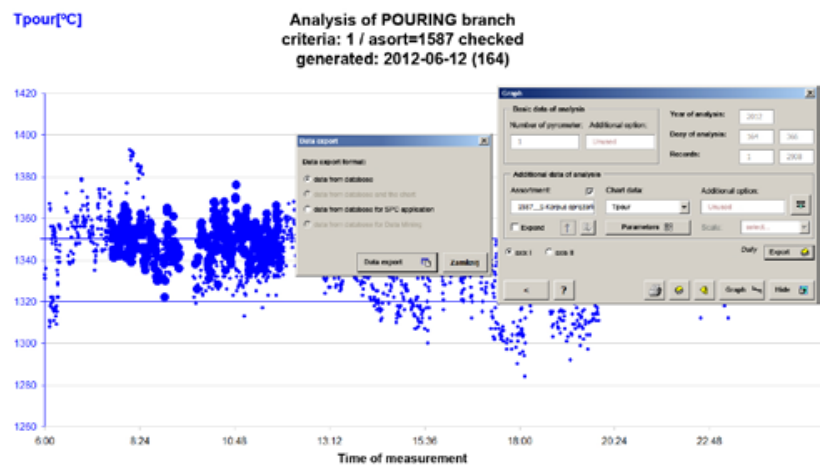

Fig. 2. Export of data and run chart diagram for design of "trial pilot” (pouring temperature by pyrometer)

Initially, a standard analysis of values of parameters from selected production "branch" recorded using KMESQ must be performed, according to assumed search filters. It is crucial to create a Run Chart, which will be a base for the "pilot trial". Such chart with indicated assortment type is shown in the Fig. 2. On the chart, an 'Export' option is shown. Exported data (appropriately prepared for SPC application with own data format *.spcdata) should be opened in the KMESQ-SPC system. The following stages are necessary: data import, selection of module of the production "branch" (in the presented example - Pouring, system of measurement of liquid alloy temperatures using pyrometer) and selection of control chart type for the "pilot trial". The next stages (performed interactively) are related to data processing - among other things, it is possible to remove outliers or trends which can be explained and described (e.g. with a malfunction of a device). The Fig. 3 shows an example of a prepared control chart, as a result of work in the module "Design of pilot trial". It is an exemplary diagram with control limits.

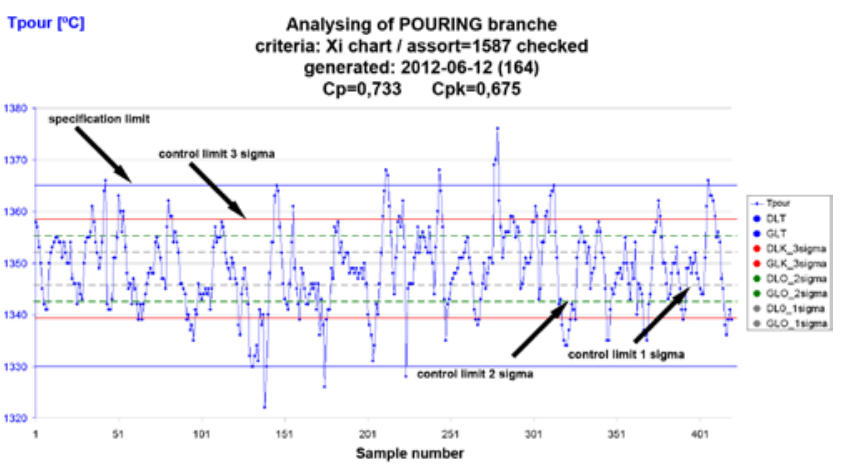

Fig. 3. Exemplary Shewhart control chart with marked control limits on levels of 3 sigma, 2 sigma and 1 sigma. Specification limits defined by "branch specialists” are shown only as visual reference (it is not always recommended)

\section{Summary, final guidelines}

The paper presents a specificity of complex foundry processes versus possibilities of SPC methods (on this stage, only a "pilot trial” was designed) for assessment of stability of parameters of processes and in future for evaluation of final quality of casting production. It has been emphasized, how relevant is to have access to real and reliable source data as a necessary condition of SPC tools application in a foundry. Integration of SPC system with previously designed system for data acquisition and exploration has been proposed [26]. Databases from particular production "branches" should be complete for particular series of pours (analyzed by KMESQ-SPC) and four mentioned "branches". Then the relation between assessments of stability and final quality may bring valuable observations.

The most important feature making the SPC application in foundry distinctive is a fact, that increase or decrease of the parameter value beyond the specification limits does not mean disqualification of the end product quality-wise. Editorial works on the software and implementation of subsequent modules of KMESQ-SPC are in progress. It should be added, that because of "police" character of the A\&DM systems, despite increasing approbation mainly thanks to a possibility of performing quick analyses, they are not generally accepted in foundries on all workplaces. It is a phenomenon of a distinct psychological aspect.

\section{Acknowledgement}

The paper was realized during doctoral thesis grant N508 526538, financed by Polish Ministry of Science and Higher Education. 


\section{References}

[1] StatSoft® Poland, (2012), SPC - Statistical Process Control, http://www.statsoft.pl/industries/spc.htm (in Polish).

[2] Perzyk, M. (2008). Computer methods for analysis and control of production processes, METRO - Metallurgical Training On-line, Education and Culture, Warsaw University of Technology (in Polish).

[3] Sika R., Ignaszak Z., Adamczak R. \& Przybyła, K. (2009). The procedure of acquisition of selected casting parameters on automatic lines in LFP Ltd., Paper during XV International Symposium Modeling of casting and foundry processes, October 23, 2009, Poznań-Leszno (Poland).

[4] Sika, R. \& Ignaszak, Z. (2009). Aspect of the acquisition and initial development of heterogeneous data for data mining systems on the example of the foundry, ed. Archives MT\&A, Poznan (in Polish)

[5] Sika, R. \& Ignaszak, Z. (2008). Data mining in the foundry industry - problem of heterogeneous data recording and their collection, Paper on XIV International Symposium Modeling of casting and foundry processes, 25th October 2008, Poznan-Srem (in Polish).

[6] Sika, R. \& Ignaszak, Z. (2008). Implementation of the KMES Quality system for data acquisition and processing on the example of chosen foundry. Archives of Foundry Engineering. 8 (3), 97-102.

[7] Sika, R. \& Ignaszak, Z. (2009). LFP Data Analysis - system to optimize the quality of production processes in the foundry, user guide. Poznan-Leszno 2009 (in Polish).

[8] Sika, R. \& Ignaszak, Z. (2006). After implementation KonMas-final prgram - its use to analyze of castings production in the W6 section - Iron Foundry in Srem, XI International Sympozjum - Modeling of casting and foundry processes, Poznan-Srem, October 2006 (in Polish).

[9] Sika, R. (2006). Studies on the structure of the SAP R / 3 and the possibility of its adaptation to the management and quality control in the Iron Foundry in Srem, diploma thesis under Z. Ignaszak supervision, PP, 2006 (in Polish).

[10] Sika, R. \& Ignaszak, Z. (2010). KMESQ - original data acquisition system contains modules for Iron Foundry in Srem industry and its usefulness for analyzing the quality of the final products, XV International Symposium Modeling of Casting and Foundry Processes, Poznan-Srem, 2010 (in Polish).

[11] Ignaszak, Z. \& Sika, R. (2008). System for exploration of selected production data and its testing in a foundry. Ed. Archive MT \& A, Poznan. 28 (1), 61-72 (in Polish).

[12] Ignaszak, Z. \& Ciesiółka, J. (2004). Identification of discontinuities defects in cast iron in terms of reception conditions and quality criteria, Proceedings: X Seminarium Nondestructive Testing Materials, Zakopane, 16-19 March 2004 (in Polish).
[13] Ignaszak, Z. \& Ciesiółka, J. (2007). Examples and error analysis to identify the types of discontinuities in castings, Proceedings: XIII Seminarium Nondestructive Testing Materials, Zakopane, 13-16 March 2007 (in Polish).

[14] Ignaszak, Z. \& Ciesiółka, J. (2005). Problems of identifying of homogeneity and continuity of the structures in castings using NDT methods in terms of selected mechanical properties, Proceedings: XI Seminarium Nondestructive Testing Materials, Zakopane, 8-11 March 2005 (in Polish).

[15] Ignaszak, Z. \& Ciesiółka, J. (2006). The importance of synergies of knowledge in the identification and interpretation of certain defects in castings on the example of ductile cast iron,, Proceedings: XII Seminarium Nondestructive Testing Materials, 14-17 March 2006 (in Polish).

[16] Hamrol, A. (2012). Quality assurance in the production processes. Poznan University of Technology, Poznan, 1995 (in Polish).

[17] The British Standards Institution (2012), Assessment and Certification - ISO/TS 16949: Automotive, http://www.bsigroup.pl/pl/Auditowanie-i-certyfikacja/, (in Polish).

[18] Polish Committee for Standardization, (2002) Technical Specifications ISO/TS 16949. Quality management system Particular requirements for the application ISO 9001:2000 in the automobile industry in series production and the production of spare parts, second edition, (in Polish).

[19] Perzyk, M. (2008). Data mining in the foundry. Opportunities, problems, projects. XI International Symposium Modeling of casting and foundry processes, October 26-27, 2008, Poznan-Srem (in Poland).

[20] Sika, R. \& Ignaszak, Z. (2011). Data acquisition in modeling using neural networks and decision trees. Archives of Foundry Engineering. 1 (2), 112-123.

[21] Hand, D., Mannila, H. \& Smyth P. (2001). Principles of Data Mining. Massachusetts Institute of Technology, USA.

[22] Ignaszak, Z., \& Ciesiółka, J. (2003). Validation of the model, the formation of shrinkage defects in castings using NDT methods. Proceedings: IX Nondestructive Testing Materials, Zakopane, 11-14 ${ }^{\text {th }}$ march 2003 (in Polish).

[23] Wyrozumski, T. (2003). How to make the data are clean? IX conference PLOUG, Koscielisko, October 2003, http://ploug.org.pl/konf_03/ (in Polish).

[24] Henry, R., Neave, D. \& Wheeler, J. (1996). Shewhart's Charts and the Probability Approach, $9^{\text {th }}$ Annual Conference of the British Deming Association, 15 May 1996.

[25] Ignaszak, Z. (2011). Conditions and prospects for nondestructive testing of castings before they use, part II. Review of Welding. 13, (in Polish).

[26] Sika, R. \& Ignaszak Z. (2012). Applications of SPC in foundry with examples, (in progress, prepared for publication). 